\title{
PRODUK SAMPING KULIT KOPI ARABIKA DAN ROBUSTA SEBAGAI SUMBER POLIFENOL UNTUK ANTIOKSIDAN DAN ANTIBAKTERI
}

\author{
By-product of Arabica and Robusta Coffee Husk as Polyphenol Source \\ For Antioxidant and Antibacterial
}

\author{
Enny Sholichah ${ }^{1 *}$, Rizky Apriani ${ }^{2 *}$, Dewi Desnilasari ${ }^{1}$, Mirwan A. Karim ${ }^{1}$, dan Harvelly ${ }^{2}$ \\ ${ }_{1}^{1}$ Pusat Penelitian Teknologi Tepat Guna, Lembaga IImu Pengetahuan Indonesia \\ ${ }^{2}$ Jurusan Tekologi Pangan, Fakultas Teknik, Universitas Pasundan \\ e-mail: enny.sh002@gmail.com
}

\begin{abstract}
Coffee husks are coffee processing by-product that can be processed to be a healthy beverage because it contains polyphenols, the bioactive compound which act as antioxidants and antibacterial. Its extraction method affected the content of active compounds in cascara. This research studied about the effect of cascara extraction process in 3 temperature levels $\left(75^{\circ} \mathrm{C}, 85^{\circ} \mathrm{C}\right.$, and 95 ${ }^{\circ} \mathrm{C}$ ) and 3 concentration levels (1:100, 2:100, and 3:100) for Arabica and Robusta coffe towards the bioactive content of polyphenols, antioxidant activity, and antibacterial activity. The results showed that cascara Arabica extract contained the highest polyphenol content $(2.381 \%)$ at $85{ }^{\circ} \mathrm{C}$ and antioxidant activity (33.5\%) at $75^{\circ} \mathrm{C}$ each at a ratio of 2:100. The best cascara Robusta extraction based on the content of polyphenols (8.089\%) is at $85^{\circ} \mathrm{C}$ with a ratio of 2:100, while based on the antioxidant activity $(57.5 \%)$ is at a temperature of $75^{\circ} \mathrm{C}$ and a ratio of 2:100 and 3:100. Cascara Arabica antibacterial activity is greater than Robusta. Cascara Arabica at a temperature of $75-95^{\circ} \mathrm{C}$ in 3 concentrations did not experience a significant change in antibacterial activity in the range of $91.02-97.6 \%$. The highest cascara Robusta antibacterial activity occurred at $95^{\circ} \mathrm{C}$ in concentration of $3: 100$ was $97.16 \%$.
\end{abstract}

Keywords: antioxidant, antibacterial, by-product of coffee, polyphenol

Abstrak: Kulit kopi sebagai produk samping pengolahan kopi dapat dimanfaatkan menjadi produk minuman kesehatan karena mengandung polifenol yang merupakan senyawa bioaktif untuk antioksidan dan antibakteri. Kondisi proses ekstraksi menentukan kandungan bahan aktif dalam minuman cascara. Penelitian ini mempelajari tentang pengaruh proses ekstraksi cascara dengan 3 variabel suhu $\left(75^{\circ} \mathrm{C}, 85^{\circ} \mathrm{C}\right.$, dan $\left.95^{\circ} \mathrm{C}\right)$ dan konsentrasi $(1: 100,2: 100$, dan $3: 100)$ untuk 2 jenis kopi yaitu arabika dan robusta terhadap kandungan bioaktif senyawa polifenol, aktivitas antioksidan, dan aktivitas antibakteri. Hasil penelitian menunjukkan bahwa ekstraksi cascara arabika menghasilkan kandungan polifenol terbaik $(2,381 \%)$ pada suhu $85^{\circ} \mathrm{C}$ dan aktivitas antioksidan $(33,5 \%)$ pada suhu $75^{\circ} \mathrm{C}$, masing-masing pada perbandingan 2:100. Ekstraksi cascara robusta terbaik pada suhu $85^{\circ} \mathrm{C}$ dan perbandingan 2:100, dimana kandungan polifenol (8,089\%) sedangkan aktivitas antioksidan ( $57,5 \%$ ) pada suhu $75^{\circ} \mathrm{C}$ serta perbandingan 2:100 dan 3:100. Aktivitas antibakteri cascara arabika lebih besar dari robusta. Cascara arabika pada suhu $75-95^{\circ} \mathrm{C}$ dengan 3 konsentrasi tidak mengalami perubahan aktivitas antibakteri secara signifikan yaitu pada kisaran 91,02-97,6\%. Aktfitas antibakteri cascara robusta tertinggi pada suhu ekstraksi $95^{\circ} \mathrm{C}$ konsentrasi $3: 100$ yaitu $97,16 \%$.

Kata kunci: antioksidan, antibakteri, by-product kopi, polifenol

\section{PENDAHULUAN}

Negara berkembang termasuk Indonesia adalah pengekspor kopi terbesar di dunia (Valduga et al., 2018). Produksi kopi di Indonesia didominasi oleh perkebunan rakyat yang mencapai 636,7 ribu ton pada tahun 2017 dan telah diekspor ke lima benua (BPS, 2017). Jenis kopi yang ada di Indonesia adalah Arabika dan Robusta dengan total produksi pada tahun 2017 berturut-turut adalah 173.765 ton dan 463.775 ton (Dirjen
Perkebunan, 2017). Kondisi geografis, perbedaan sifat tanah, mikrolimat serta pola bercocok tanam petani kopi mempengaruhi produktifitas kopi yang dihasilkan (Kurniawan, 2017) serta komposisi komponen kimia yang terkandung dalam ceri kopi (Bonilla-Hermosa et al., 2014).

Kulit kopi diperoleh dari pengolahan buah kopi atau ceri kopi yang melalui tahapan pulping baik proses basah yaitu ceri kopi, pencucian, pulping (Widyotomo, 2013) 
ataupun proses kering yaitu pencucian, penjemuran, dan pulping (Aisyah, 2018). Proses pulping menghasilkan produksamping kulit kopi (coffee husk) berkisar 45\% (Esquivel \& Jiménez, 2012), atau dalam setiap ton buah basah ceri kopi akan dihasilkan $200 \mathrm{~kg}$ kulit kopi kering (Widyotomo, 2013). Kulit kopi merupakan bahan yang dapat dimanfaatkan sebagai bahan penghasil kafein, polifenol, dan bioetanol (Bonilla-Hermosa et al., 2014) serta antioksidan dan antimikroba (JiménezZamora et al., 2015). Senyawa fenolik yang terdapat dalam pulp kopi yaitu asam klorogenat (asam 5-caffeoylquinic acid 4,2\%), epikatekin (21,6\%), 3,4 dicaffeoylquinic acid (5,7\%), 3,5 dicaffeoylquinic acid (19,3\%), 4,5 dicaffeoylquinic acid (4,4\%), katekin (2,2\%), ptorocatechuic acid $(1,6 \%)$, dan ferulic acid $(1,0 \%)$ (Ramirez $\square$ Martinez, 1988). RamirezCoronel et al., (2004) melaporkan ada empat kelompok utama polifenol dalam kopi Arabika, yaitu flavan-3-ols, hydroxycinnamic acid, flavanols, dan anthicyanidins. Kulit kopi Robusta terdapat polifenol, antosianin, vitamin C, betakaroten, gula reduksi, dan antioksidan (Ariadi \& Windrati, 2015). Ekstrak daging buah ceri kopi Robusta memiliki aktivitas penghambatan pertumbuhan bakteri S. aureus dan E. coli (Harahap, 2018).

Besarnya jumlah kulit kopi yang dihasilkan dari proses pengolahan kopi serta potensi manfaat dari kulit kopi menjadi peluang pengembangan produkproduk turunan dari kulit kopi salah satunya adalah minuman cascara. Cascara adalah minuman teh ceri kopi yang dibuat dari kulit ceri kopi yang bersifat menyegarkan dan menstimulasi karena kandungan kafein dan komponen lain yang mirip dengan biji kopi (Heeger et al., 2017). Cascara yang dihasilkan dari ceri kopi arabika dapat mencapai 40\% (Aisyah, 2018).

Kandungan senyawa fenolat dalam ekstrak kopi hijau sangat dipengaruhi oleh kondisi penyeduhan (Purwakhdyana et al., 2018), demikian juga dalam proses ekstraksi atau penyeduhan cascara. Proses ekstraksi cascara meliputi suhu, waktu ekstrasi serta perbandingan antara volume air yang ditambahkan dengan jumlah cascara yang digunakan. Suhu ekstraksi merupakan salah satu faktor yang berpengaruh terhadap kandungan komponen bahan aktif dalam suatu matriks sehingga perlu dibatasi pada suhu $80-90{ }^{\circ} \mathrm{C}$ agar tidak terjadi kerusakan senyawa polifenol (Kristiandi, 2018). Faktor lain yang mempengaruhi kandungan senyawa fenolik dalam cascara adalah bahan baku yaitu ceri kopi, dimana perbedaan daerah, varietas, dan metode proses pengolahan ceri kopi menghasilkan perbedaan kandungan senyawa fenolik dan kafein. (Heeger, et al., 2017) melaporkan bahwa ceri kopi dari negara Kongo memiliki kandungan polifenol, aktivitas antioksidan, dan kafein yang tertinggi dibandingkan dari Honduras dan Salvador.

Maserasi kulit kopi arabika dan robusta menggunakan pelarut yaitu campuran etanol-aquades (1:1) dan penambahan asam sitrat $5 \%$ dengan variasi waktu 15 dan 30 menit (Ariadi \& Windrati, 2015). Etanol merupakan pelarut organik yang tidak diperkenankan untuk dikonsumsi secara langsung. Oleh karena itu, studi tentang kondisi ekstraksi cascara dengan pelarut air sangat dibutuhkan untuk menghasilkan produk cascara yang dapat dikonsumsi secara langsung. Penelitian ini mempelajari kondisi ekstraksi meliputi suhu dan waktu ekstraksi serta pengaruhnya terhadap kandungan polifenol, aktivitas antioksidan, dan antimikroba dari cascara yang dibuat dari kopi arabika dan robusta.

\section{METODOLOGI}

Bahan utama dalam penelitian ini meliputi ceri kopi varietas arabika yang diperoleh dari petani kopi desa Bokanegara, kecamatan Cisalak, Subang, Jawa Barat dan ceri varietas robusta yang diperoleh dari petani kopi di Kabupaten Sumba Barat Daya, Nusa Tenggara Timur. Bahan kimia yang digunakan adalah etanol, pereaksi folin ciocalteau $10 \%$, natrium karbonat, etanol, asam galat, 1,1-diphenyl-method 2-pikrilhidrazil (DPPH) (Sigma aldrich), Quersetin Natrium Borth, BPW (Buffered Pepton Water), PCA (Plate Count Agar), dan akuades. 
Peralatan proses yang digunakan adalah pulper kopi sistem manual, cabinet dryer, blender, neraca analitik, oven Memmert, spektrofotometer UV-Vis Shimadzu 1900, Laminar Air Flow (LAF), autoclave- Hirayama, vortex mixer, magnetic stirrer, termometer, jarum ose, bunsen, dan inkubator.

\section{Penyiapan bahan}

Ceri kopi arabika dan robusta disortasi untuk memisahkan ceri kopi yang cacat dan over ripe, selanjutnya dicuci dan dikupas dengan alat pulper manual. Kulit ceri kopi dikeringkan menggunakan cabinet dryer pada suhu $45^{\circ} \mathrm{C}$. Tahap selanjutnya adalah pengecilan ukuran dengan blender dan pengemasan dalam plastik PP 0,6 mm.

\section{Ekstraksi}

Proses ekstraksi kulit kopi kering dilakukan dengan 2 faktor yaitu suhu dan konsentrasi perbandingan kulit kopi dengan air $(w / v)$. Tiga level variasi yang digunakan yaitu $75^{\circ} \mathrm{C}$, $85^{\circ} \mathrm{C}$, dan $95^{\circ} \mathrm{C}$. Adapun perbandingan kulit kopi dengan air (w/v) adalah (1:100), (2:100), dan (3:100). Setiap perlakuan dilakukan dengan cara menyeduh $0,1 \mathrm{~g}$ kulit kopi kering dalam air sesuai dengan kondisi penyeduhan (suhu dan volume air) menggunakan alat magnetic stirrer dengan putaran $190 \mathrm{rpm}$ selama 15 menit.

\section{Analisis kandungan polifenol}

Pengukuran kandungan polifenol mengacu pada metode analisis polifenol dalam SNI 3945:2016 (BSN, 2016). Standar yang digunakan adalah asam galat dengan konsentrasi 10, 20, 30, 40, dan 50 ppm. Tahap pengukuran polifenol yaitu $1 \mathrm{ml}$ larutan standar ditambah $5,0 \mathrm{ml}$ pereaksi Fenol Folin-ciocalteu $10 \%$ dan didiamkan selama 3-8 menit, selanjutnya ditambahkan $4,0 \mathrm{ml}$ larutan $\mathrm{Na}_{2} \mathrm{CO}_{3} 7,5 \%$ ditutup dan dikocok, lalu didiamkan selama 50 menit pada suhu ruang. Akuades digunakan sebagai larutan blanko. Larutan sampel diberikan perlakuan sebagaimana larutan standar. Tahap berikutnya adalah pengukuran absorbansi larutan blanko, standar, dan sampel menggunakan spektrofotometerUV-Vis shimadzu 1900 pada panjang gelombang $765 \mathrm{~nm}$. Perhitungan kadar polifenol berdasarkan persamaan 1 .

$$
\text { Kadar polifenol }(\%)=\frac{\left(\mathrm{D}_{\text {sampel }}-\mathrm{D}_{\text {intersep }}\right) \times \mathrm{V}_{\text {sampel }} \times \mathrm{D}}{\mathrm{S}_{\text {std }} \times \mathrm{m}_{\text {sampel }} \times 10000 \times \mathrm{W}_{\mathrm{DM} \text { sampel }}} \times 100 \%
$$

\section{Keterangan :}

$$
\begin{aligned}
\mathrm{D}_{\text {sampel }}= & \text { absorbansi larutan sampel } \\
\mathrm{D}_{\text {intersep }}= & \text { absorbansi yang diperoleh untuk } \\
& \text { konsentrasi larutan blanko } \\
\mathrm{S}_{\text {std }} & \text { slove kurva kalibrasi } \\
\mathrm{m}_{\text {sampel }}= & \text { massa sampel, dinyatakan dalam } \\
& \text { gram } \\
\mathrm{V}_{\text {sampel }}= & \text { volume larutan ekstraksi sampel, } \\
& \text { dinyatakan dalam mililiter } \\
\mathrm{D} & \text { faktor pengenceran } \\
\mathrm{W}_{\text {DM sampel }}= & \text { bobot sampel atas dasar bahan } \\
& \text { kering, dinyatakan dalam \% (fraksi } \\
& \text { masa) }
\end{aligned}
$$

\section{Analisis aktivitas antioksidan}

Aktivitas antioksidan ekstrak kulit kopi dilakukan dengan menggunakan metode DPPH (Dhianawaty \& Ruslin, 2015).
Sebanyak $25 \mathrm{mg}$ ekstrak dilarutkan dengan metanol dalam labu ukur $25 \mathrm{ml}$ sebagai larutan induk 1000 ppm. Standar quercetin dibuat dalam beberapa konsentrasi yaitu 0 ; 5; 10; 15; 20; dan 30 ppm. Sampel dibuat dengan mengencerkan setiap ekstrak yang diperoleh untuk setiap perlakuan dalam konsentrasi $50 \mathrm{ppm}$. Masing-masing standar dan sampel ditambah $5 \mathrm{ml}$ larutan DPPH 0,5 $\mathrm{mM}$. Larutan blanko adalah larutan DPPH 0,5 $\mathrm{mM}$. Absorbansi DPPH dalam blanko diukur dengan spektrofometer UV-Vis pada panjang gelombang $516 \mathrm{~nm}$, dengan selang waktu 5 menit mulai dari 0 menit sampai 30 menit. Absorbansi DPPH dalam setiap larutan diukur. Kemudian antioksidan diukur pada menit ke-30. Aktivitas antioksidan dihitung berdasarkan persamaan 2 . 


$$
\% R S A=\frac{\mathrm{A}_{\text {kontrol }}-\mathrm{A}_{\text {sampel }}}{\mathrm{A}_{\text {kontrol }}} \times 100 \% \ldots \ldots \ldots .2
$$

\section{Keterangan :}

$\mathrm{A}_{\text {kontrol }}=$ Absorbansi blanko (tidak mengandung sampel)

$A_{\text {sampel }}=$ Absorbansi sampel.

\section{Analisis Aktivitas Antibakteri}

Aktivitas antimikroba dilakukan berdasarkan metode Dilusi yang dilakukan oleh (Kokoska, et al., 2002) dengan modifikasi. Suspensi E.coli yang mengandung bakteri berkisar $10^{5}-10^{6} \mathrm{CFU} /$ $\mathrm{ml}$ diujikan ke ekstrak cascara. Larutan uji dibuat dengan menambahkan $5 \%$ ekstrak cascara dengan 95\% suspensi E.coli. Kemudian larutan tersebut diinkubasi selama 30 menit. Setelah itu, Iarutan uji dihitung jumlah bakterinya menggunakan metode
"Total Plate Count", begitu juga larutan suspensi E.coli tanpa ekstrak. Persentase penurunan jumlah bakteri dihitung dengan menghitung selisih suspensi uji dengan suspensi E.coli, dibagi dengan jumlah suspensi E.coli dan dikalikan dengan $100 \%$.

\section{Analisis statistik}

Penelitian ini dilakukan menggunakan Rancangan Acak Kelompok (RAK) dengan 2 faktor dan 3 taraf. Faktor penelitian meliputi suhu ekstraksi dengan 3 taraf yaitu $75^{\circ} \mathrm{C}, 85^{\circ} \mathrm{C}$, dan $95^{\circ} \mathrm{C}$, sedangkan konsentrasi digunakan 3 taraf yaitu 1:100; 2:100; dan 3:100. Pola rancangan penelitian adalah $3 \times 3$ dengan 3 kali pengulangan. Data yang diperoleh untuk setiap parameter pengujian dianalisis signifikansinya dengan analisis sidik ragam (ANOVA) dengan selang kepercayaan $95 \%$ dan uji lanjut menggunakan metode Duncan.

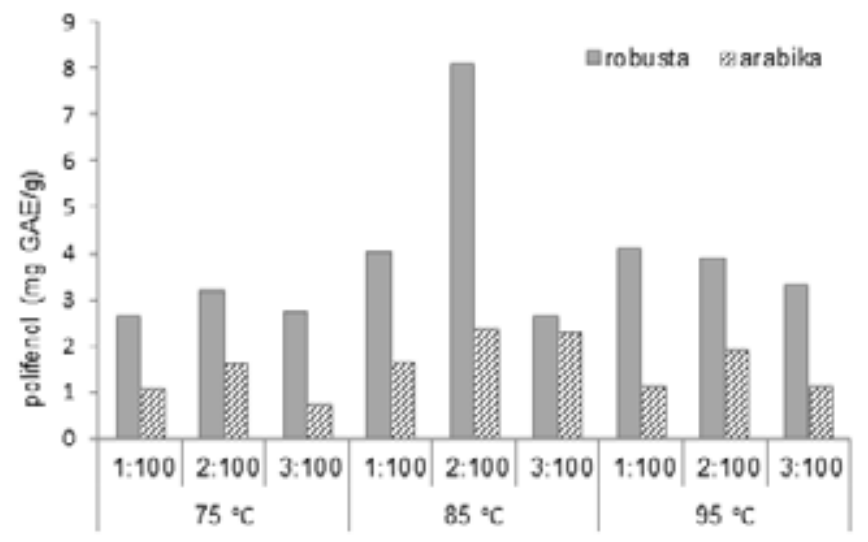

Gambar 1. Kadar polifenol dalam ekstrak cascara kopi Robusta dan Arabika

\section{HASIL DAN PEMBAHASAN}

\section{Kandungan polifenol}

Polifenol termasuk metabolit sekunder dari tanaman. Polifenol memiliki jenis senyawa yang sangat beragam serta merupakan senyawa bioaktif yang memiliki banyak manfaat bagi kesehatan manusia dan tidak toksik (Rasouli et al., 2017). Kopi sebagai sumber utama kafein mengandung banyak komponen senyawa kimia lainnya yaitu golongan karbohidrat, lipid, senyawa nitrogen, vitamin, mineral, alkaloid, dan senyawa fenolik (Valduga et al., 2018).
Kandungan polifenol dalam ekstrak cascara sangat dipengaruhi oleh teknik atau metode ekstraksi (Rasouli et al., 2017). Ekstraksi kulit ceri kopi dilakukan menggunakan air panas untuk memperoleh kadar polifenol yang optimal. Kadar polifenol dalam ekstrak cascara dinyatakan dalam $\mathrm{mg}$ asam galat ekivalen per gram sampel. Suhu ekstraksi berpengaruh signifikan terhadap kadar polifenol untuk cascara robusta dan arabika, dimana pada suhu $85^{\circ} \mathrm{C}$ diperoleh kandungan polifenol paling tinggi. Konsentrasi 2:100 menghasilkan ekstrak dengan kandungan polifenol signifikan dibandingkan 
konsentrasi kedua konsentrasi lainnya. Senyawa polifenol merupakan senyawa organik yang memiliki sifat semipolar dimana memiliki tingkat kelarutan yang baik dalam pelarut semipolar seperti etanol, metanol, asetonitril, aseton, dan n-butanol (Marcelinda et al., 2016; Tsao, 2010). Ekstraksi dengan air membutuhkan peningkatan suhu untuk mengekstrak atau melarutkan senyawa polifenol, sehingga pada suhu $85^{\circ} \mathrm{C}$ dan 95 ${ }^{\circ} \mathrm{C}$ menghasilkan ekstrak dengan kandungan polifenol lebih tinggi dibandingkan dengan suhu $75^{\circ} \mathrm{C}$. Peningkatan suhu penyeduhan dimungkinkan mampu menghidrolisis glikosida yang terikat dalam senyawa polifenol. Senyawa polifenol umumnya dalam bentuk glikosida sebagaimana hasil penelitian Al-youssef (2017) menyatakan bahwa hasil skrining fitokimia dalam kulit kopi yang diekstraksi dengan etanol mengandung senyawa alkaloid, glikosida/karbohidrat, flavonoid, saponin, triterenes/sterol, tannin, and senyawa volatil.

Kandungan polifenol dalam cascara robusta lebih tinggi dari arabika pada setiap kondisi proses penyeduhan, sebagaimana hasil penelitian Ariadi (2013) melaporkan bahwa kandungan polifenol pada cascara robusta yang dimaserasi menggunakan pelarut air:etanol selama 15 menit lebih tinggi dibandingkan dengan cascara arabika. Ekstraksi cascara pada suhu $85{ }^{\circ} \mathrm{C}$ dan konsentrasi 2:100 menghasilkan ekstrak dengan kandungan polifenol tertinggi untuk kedua jenis cascara. Cascara robusta sebesar 2,65-8,09 $\mathrm{mg}$ GAE/g dan arabika 0,76-2,38 $\mathrm{mg}$ GAE/g. Kadar polifenol yang diperoleh pada cascara robusta dari kabupaten Sumba Barat Daya lebih besar dari hasil penelitian Bonilla-Hermosa et al., (2014) dimana mereka mengekstrak pulp ceri kopi dari daerah Minas Gerais-Brazil menggunakan air panas menghasilkan ekstrak dengan kandungan polifenol 2.62 (g/100). Heeger et al., (2017)melaporkan bahwa kandungan total polifenol tertinggi dalam kopi berasal dari Kongo sebesar 9,17 mg GAE/g DM dibandingkan dari daerah Salvador dan Honduras.
Kadar polifenol menjadi salah satu parameter mutu produk minuman berbahan baku teh yaitu teh hitam celup min. 9\% (BSN, 2014) dan teh hijau min. 15\% (b/b) (BSN, 2016). Kandungan polifenol dalam ekstrak cascara $\pm 1 \%$ lebih rendah dari teh hitam celup. Secara umum senyawa polifenol dikelompokkan dalam 2 kelompok besar yaitu flavonoid dan non flavonoid atau asam fenolat (Tsao, 2010). Senyawa polifenol dalam kulit ceri kopi ada 4 golongan besar yaitu flavan-3-ols, asam hidrosinamat, flavonol dan antosianin. Pengupasan kulit ceri kopi yang masih merah menggunakan proses basah menghasilkan sianidin-3-rutinosida, sianidin-3-glukosida, dan aglikonnya sebagai antosianin utama (Esquivel \& Jiménez, 2012). Dengan demikian, kulit ceri kopi yang diproses menjadi cascara merupakan sumber polifenol yang dapat bermanfaat untuk produk pangan maupun farmasi.

\section{Aktivitas antioksidan}

Bahan antioksidan adalah bahan atau senyawa yang memiliki kemampuan untuk menghambat, menunda atau mencegah proses oksidasi bahan lain yang mudah teroksidasi (Santoso, 2016). Pengujian aktivitas antioksidan menggunakan metode DPPH (1,1-diphenyl-2-pikrilhidraz), dimana aktivitas antioksidan didasarkan pada daya tangkap senyawa terhadap radikal bebas. DPPH sebagai sumber radikal bebas merupakan senyawa radikal yang stabil pada suhu ruang, mengalami perubahan warna apabila bereaksi dengan senyawa antioksidan sehingga banyak digunakan sebagai metode pengujian aktivitas antiokasidan. Struktur kimia DPPH dapat terlihat pada gambar 2 . 
<smiles>O=[N+]([O-])c1cc([N+](=O)[O-])c(NN(c2ccccc2)c2ccccc2)c([N+](=O)[O-])c1</smiles>

A<smiles>O=[N+]([O-])c1cc([N+](=O)[O-])c(N(c2ccccc2)c2ccccc2)c([N+](=O)[O-])c1</smiles>

B
Gambar 2. Struktur Kimia DPPH (a) non radikal, (b) radikal (Molyneux, 2004)

Gambar 3 menunjukkan bahwa ekstrak cascara robusta memiliki aktivitas antioksidan lebih besar dibandingkan dengan arabika pada setiap kondisi penyeduhan. Aktivitas antioksidan cascara robusta sebesar 39-57\%, sedangkan arabika adalah 22,5-33,5\%. Aktivitas antioksidan cascara arabika lebih rendah dibandingkan dalam pulp berdasarkan hasil penelitian Ariadi \& Windrati (2015) yang menunjukkan bahwa aktivitas antioksidan pulp kopi arabika sebesar $51 \%$. Hal ini dapat disebabkan proses pengeringan dengan suhu $50{ }^{\circ} \mathrm{C}$ pada pembuatan cascara telah merusak sebagian bahan aktif sehingga aktivitas antioksidannya menurun. Penurunan aktivitas antioksidan terjadi secara signifikan pada cascara robusta dan arabika yang diseduh pada suhu $85^{\circ} \mathrm{C}$ dan $95^{\circ} \mathrm{C}$. Konsentrasi 2:100 pada setiap suhu ekstraksi signifikan menghasilkan ekstrak dengan aktivitas antioksidan lebih tinggi.

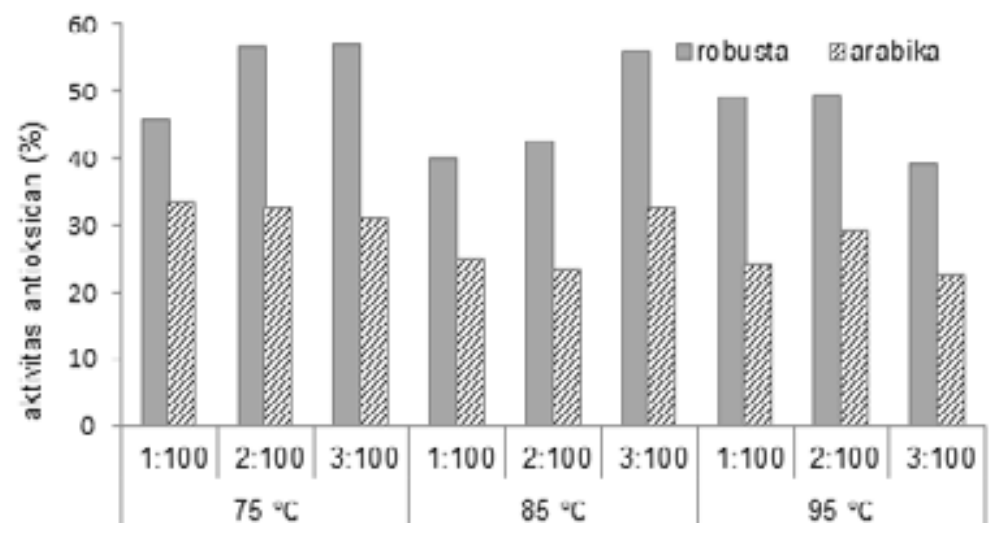

Gambar 3. Aktivitas antioksidan ekstrak cascara kopi Robusta dan Arabika

Senyawa polifenol berfungsi sebagai antioksidan melalui mekanisme antioksidan primer, yaitu memutus rantai proses oksidasi (Santoso, 2016). Gugus hidroksil (-OH) pada flavonoid khususnya pada cincin B posisi 2; 3; dan 4 merupakan gugus aktif untuk menangkap radikal bebas. Senyawa polifenol dalam cascara menurut beberapa penelitian yang telah dilakukan adalah flavan-3-ols, asam klorogenat, flavonol dan antocyanidin. Flavan-3-ols atau dikenal dengan katekin memiliki stuktur dasar 2-fenil benzopiran. Flavan-3-ols yang tersubstitusi oleh 2 gugus hidroksil pada cincin $A$ di posisi meta dikenal dengan epikatekin dan epikatekin galat. Epigalokatekin dan epigalokatekin galat adalah katekin yang memiliki 3 gugus hidroksil yaitu 5,7-meta- dihidroksi pada cincin A dan C-3 dari cincin C (Cartalade et al., 2003). Strukturnya dapat terlihat di gambar 4. Heeger et al., (2017) melaporkan dua senyawa fenolik yang dominan dalam cascara adalah asam protokatekuit dan asam klorogenat sebesar 85,0 dan $69,6 \mathrm{mg} / \mathrm{L}$. Senyawa-senyawa tersebut memiliki kestabilan pada suhu 85 ${ }^{\circ} \mathrm{C}$ sehingga aktivitas antioksidannya relatif masih besar. 

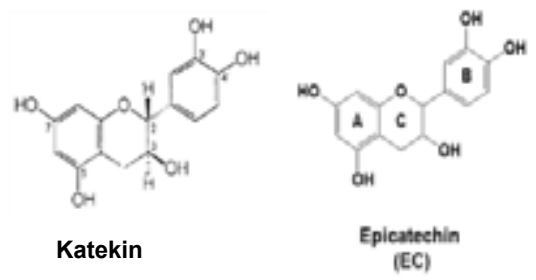
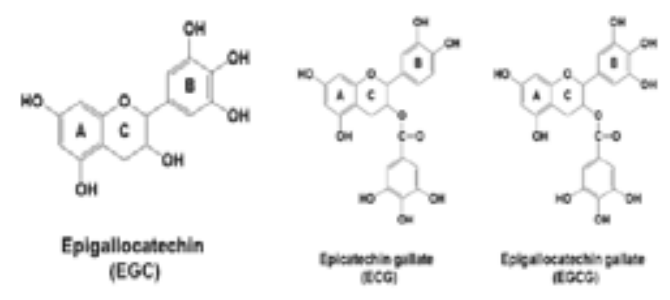

Gambar 4. Struktur senyawa golongan katekin

\section{Aktivitas Antibakteri}

Aktivitas antibakteri dilakukan dengan metode dilusi menggunakan bakteri E.coli. Bakteri E.colimerupakan bakteri gram negatif yang hidup secara alami di lingkungan (flora normal) sekitar manusia serta digunakan sebagai salah satu indikator sanitasi. Efek infeksi bakteri E.coli pada manusia menyebabkan gangguan pencernaan seperti diare (Zikra et al., 2018). Ekstrak cascara memberikan aktivitas antibakteri terhadap E. coli, dimana suhu ekstraksi dan konsentrasi tidak berpengaruh signifikan terhadap aktivitas antibakteri untuk kedua jenis cascara (Gambar 5). Hal ini berarti proses penyeduhan dengan konsentrasi 1:100 pada suhu $75^{\circ} \mathrm{C}$ telah menghasilkan ekstrak cascara yang memiliki daya hambat bakteri. Secara deskriptif terlihat bahwa ekstrak cascara arabika relatif memiliki aktivitas antibakteri yang lebih tinggi daripada robusta. Hasil ini tidak selaras dengan hasil polifenol dan antioksidan yang menunjukkan kebalikannya. Hal ini diduga disebabkan oleh bakteri gram negatif yang lebih tahan terhadap senyawa hidrofobik (fenol dan tanin) karena senyawa tersebut susah untuk masuk ke membran sel bakteri gram negatif yang mengandung tinggi fosfolipid. Beberapa penelitian menemukan bahwa yang berperan besar di dalam aktivitas antibakteri melawan bakteri gram negatif untuk limbah kopi adalah kafein dan melanoidin. Melanoidin menghambat bakteri melalui mekanisme chelating logam (Duangjai et al., 2016).

Cascara dapat memberikan aktivitas penghambatan pertumbuhan $E$. coli disebabkan adanya kandungan bahan aktif yang kompleks. Cascara dari limbah kopi mengandung senyawa asam quinat, asam malat, asam klorogenik, tanin, asam hidroksinamik (termasuk grup hidroksil pada asam klorogenik), dan lebih banyak kafein yang memiliki aktivitas antibakteri (Duangjai et al., 2016). Penelitian Ramirez-Coronel et al., (2004), Al-youssef (2017) dan Ariadi (2013) menyebutkan bahwa di dalam buah kopi memiliki senyawa fenolik berupa flavanols, hydroxycinnamic acid, dan tannin yang terekstrak dalam ekstrak. Suatu bahan mampu untuk menghambat atau membunuh mikroba dikarenakan adanya kandungan garam-garam logam, senyawa fenolik, forlmaldehida, alkohol, dan antibiotik lainnya (Pratama, 2015).

Senyawa fenolik memiliki kemampuan merusak integritas membran biologis mikroorganisme yang mempengaruhi kapasitas penghalang selektif membran dan matriks enzimatik dari mikroorganisme. Senyawa penghambat ini termasuk alkohol, aldehida, keton, dan asam (Al-Yousef \& Amina, 2018). Adapun senyawa tannin menghambat pertumbuhan bakteri dengan cara menginaktifkan adhesin mikroba (molekul yang menempel pada inang) yang terdapat pada permukaan sel dan enzim serta menggangu transport protein pada lapisan dalam sel. Tanin juga mempunyai target pada polipeptida dinding sel yang menyebabkan kerusakan dinding sel, karena tannin merupakan senyawa fenol. Senyawa fenol akan menyerang gugus polar (gugus fosfat) sehingga molekul fosfolipid akan terurai menjadi gliserol, asam karboksilat, dan asam fosfat. Hal ini menyebabkan fosfolipid tidak dapat mempertahankan bentuk membran sel, akibatnya membran akan rusak dan mengalami hambatan pertumbuhan. Aktivitas 
ini sangat selektif ketika bakteri dalam tahap pembelahan, dimana saat lapisan fosfolipid dalam kondisi yang sangat tipis, fenol dapat berpenetrasi dengan mudah dan merusak isi sel (Pratama, 2015).

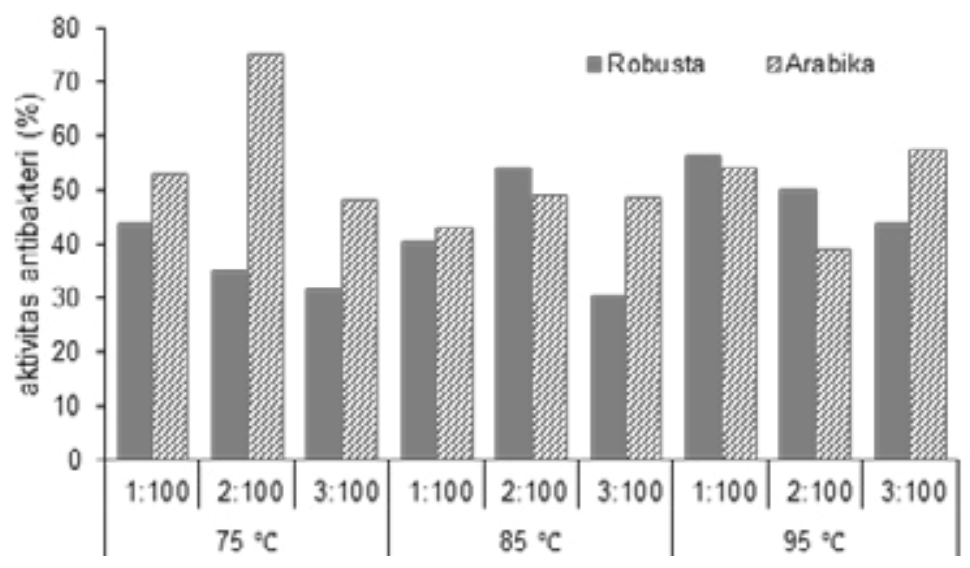

Gambar 5. Aktivitas antibakteri ekstrak cascara kopi Robusta dan Arabika

\section{SIMPULAN}

Ekstraksi cascara pada suhu $85^{\circ} \mathrm{C}$ dan konsentrasi 2:100 menghasilkan ekstrak dengan kandungan polifenol tertinggi serta aktivitas antioksidan dan antibakteri terbaik. Adapun cascara robusta dari daerah Sumba Barat Daya memiliki kandungan polifenol, aktivitas antioksidan dan antibakteri lebih tinggi dibandingkan dengan cascara arabika dari daerah Subang. Kondisi ekstraksi tersebut dapat dimanfaatkan untuk proses pengembangan produk minuman berbasis ekstrak cascara atau produk turunan cascara lainnya sehingga manfaat bahan aktif dari cascara dapat diterima.

\section{DAFTAR PUSTAKA}

1. Aisyah, N. S. 2018. Analisis Nilai Tambah Industri Pengolahan Buah Cherry Kopi (kasus di Mahkota Java Coffee Garut) Nur Syamsi Aisyah. Institut Pertanian Bogor.

2. Al-Yousef, H. M., \& Amina, M. 2018. Essential Oil of Coffee arabica L. Husks: A brilliant source of antimicrobial and antioxidant agents. Biomedical Research (India), 29(1), 174-180.

3. Al-youssef, H. M. 2017. Pharmacognostic Studies on Coffee Arabica
L . Husks: A Brilliant Source of Antioxidant Agents. European Journal of Pharmacheutical and Medical Research, 4 (1), 86-92.

4. Ariadi, Harri Prasetyo, \& Windrati, W. S. 2015. Compound Extraction of Coffee Fruit Cod: Study of Species and Maceration Duration of Coffee. Berkala IImiah Pertanian, $x, 1-5$.

5. Ariadi, Harri Prasetyto. 2013. Ekstraksi Senyawa Antioksidan Kulit Buah Kopi : Kajian Jenis Kopi dan Lama Maserasi. Skripsi, 1-46.

6. Bonilla-Hermosa, V. A., Duarte, W. F., \& Schwan, R. F. 2014. Utilization of coffee by-products obtained from semi-washed process for production of value-added compounds. Bioresource Technology, 166, 142-150. https://doi. org/10.1016/j.biortech.2014.05.031

7. BPS. 2017. Statistik Kopi Indonesia (Indonesian Coffee Statistic) 2017. (S. D. S. T. Perkebunan, Ed.). Jakarta: Badan Pusat Statistik.

8. BSN. 2014 SNI 3753:2014 Teh Hitam Celup. Indonesia: Badan Standarisasi Nasional.

9. BSN. 2016. SNI 3945: 2016 Teh Hijau. Indonesia: Badan Standarisasi Nasional. 
10. Cartalade, D., Putaux, J., \& Vernhet, A. (2003). Flavan-3-ol Aggregation in Model Ethanolic Solutions: Incidence of Polyphenol Structure , Concentration, Ethanol Content, and lonic Strength, (12), 1429-1438.

11. Dhianawaty, D., \& Ruslin. 2015. Kandungan Total Polifenol dan Aktivitas Antioksidan dari Ekstrak Metanol Akar Imperata cylindrica (L) Beauv. (Alang-alang) Total Polyphenol Content and Antioxidant Activity of Methanol Extract of Imperata cylindrica (L) Beauv. (Alang-alang) Root. Majalah Kedokteran Bandung, $47(1)$.

12. Dirjen Perkebunan. 2017. Statistik Perkebunan Indonesia 2015-2017 Kopi. (D. D. Hendaryati \& Y. Arianto, Eds.). Jakarta: Kementrian Pertanian.

13. Duangjai, A., Suphrom, N., Wungrath, J., Ontawong, A., NUengchamnong, N., \& Yosboonruang, A. 2016. Comparison of antioxidant, antimicrobial activities and chemical profiles of three coffee (Coffea arabica L.) pulp aqueous extracts. Integrative Medicine Research, 5(4), 324-331. https://doi.org/10.1016/j. imr.2016.09.001

14. Esquivel, P., \& Jiménez, V. M. 2012. Functional properties of coffee and coffee by-products. Food Research International, 46(2), 488-495. https://doi.org/10.1016/j. foodres.2011.05.028

15. Harahap, M. R. 2018. Aktivitas Daya Hambat Limbah Daging Buah Kopi Robusta (Coffea robusta L.) Aceh terhadap Bakteri S. aureus dan E. coli. Jurnal Kesehatan, 9(April), 93-98.

16. Heeger, A., Kosińska-Cagnazzo, A., Cantergiani, E., \& Andlauer, W. 2017. Bioactives of coffee cherry pulp and its utilisation for production of Cascara beverage. Food Chemistry, 221, 969975. https://doi.org/10.1016/j.foodchem.2016.11.067
17. Jiménez-Zamora, A., Pastoriza, S., \& Rufián-Henares, J. A. 2015. Revalorization of coffee by-products. Prebiotic, antimicrobial and antioxidant properties. $L W T$ - Food Science and Technology, 61(1), 12-18. https:// doi.org/10.1016/j.lwt.2014.11.031

18. Kokoska, L., Polesny, Z., Rada, V., Nepo, A., \& Vanek, T. 2002. Screening of some Siberian medicinal plants for antimicrobial activity. Jour-nal of Etnopharmacology, 82, 51-53.

19. Kristiandi, W. 2018. Factors Affecting Caffein Content and Acidity of Coffee During Roasting, Grinding and Brewing: A Review. Universitas Katolik Soegijapranata.

20. Kurniawan, F. 2017. Karakterisasi dan Klasifikasi Biji Kopi Java Arabika Berdasarkan Indikator Geografis Menggunakan Metode NIR Spectroscopy dan Analisis Diskriminan. Institute Pertanian Bogor.

21. Marcelinda, A., Ridhay, A., \& Prismawiryanti. 2016. The Atioxidant Activity of Husk Coffea (Coffea sp) Extract Base on Various Levels of Polar Solvent. Jurnal of Nature Science, 5(1), 21-30.

22. Molyneux, P. 2004. The Use of the Stable Free Radical Diphenylpicrylhydrazyl (DPPH) for Estimating Antioxidant Activity. Songklanakarin Journal of Science and Technology, 26(December 2003), 211-219. https:// doi.org/10.1287/isre.6.2.144

23. Pratama, E. Y. 2015. Aktivitas Antimikroba Ekstrak Daun Buah Ginje (Thevetia peruviana) Terhadap Staphylococcus aureus Dan Candida albicans Secara In Vitro. Surakarta.

24. Purwakhdyana, Radesta Kunarto, B., Sani, E. Y., \& Pratiwi, E. 2018. Pengaruh Suhu dan Lama Waktu Ekstraksi Terhadap Sifat Kimia Kopi Hijau (Coffea canepora P.). Semarang.

25. Ramirez-Coronel, M. A., Marnet, N., Kolli, V. S. K., Roussos, S., Guyot, S., \& Augur, C. 2004. Characterization 
and Estimation of Proanthocyanidins and Other Phenolics in Coffee Pulp (Coffea arabica) by Thiolysis-HighPerformance Liquid Chromatography. Journal of Agricultural and Food Chemistry, 52(5), 1344-1349. https:// doi.org/10.1021/jf035208t

26. Ramirez Martinez, J. R. 1988. Phenolic compounds in coffee pulp: Quantitative determination by HPLC. Journal of the Science of Food and Agriculture, 43(2), 135-144. https:// doi.org/10.1002/jsfa.2740430204

27. Rasouli, H., Farzaei, M. H., \& Khodarahmi, R. 2017. Polyphenols and their benefits: $A$ review Polyphenols and their benefits: A review Hassan. International Journal of Food Properties, 00 (00), 1-42. https://doi.org/10.1080/10942912.201 7.1354017

28. Santoso, U. 2016. Antioksidan Pangan. Penerbit Gadjah Mada University Press. Yogyakarta.
29. Tsao, R. 2010. Chemistry and Biochemistry of Dietary Polyphenols, 1231-1246. https://doi.org/10.3390/ nu2121231

30. Valduga, A. T., Gonçalves, I. L., Magri, E., \& Finzer, J. R. D. 2018. Chemistry, pharmacology and new trends in traditional functional and medicinal beverages. Food Research International, (May), 1-26. https://doi. org/10.1016/j.foodres.2018.10.091

31. Widyotomo, S. 2013. Potency and Technology of Coffee Trash Diversification Product to Increase Good Quality and Added Value. Review Penelitian Kopi Dan Kakao, 1(1), 63-80.

32. Zikra, W., Amir, A., \& Putra, A. E. 2018. Identifikasi Bakteri Escherichia coli (E. coli) pada Air Minum di Rumah Makan dan Cafe di Kelurahan Jati serta Jati Baru Kota Padang. Jurnal Kesehatan Andalas, 7(2), 212-216. 